\title{
METODE PENGEMBANGAN PERANGKAT LUNAK BERBASIS MOBILE: A REVIEW
}

\author{
Firamon Syakti \\ Program Studi Teknik Informatika \\ Universitas Bina Darma \\ email :1 firamon.syakti@binadarma.ac.id \\ Jl. A. Yani No. 3, Palembang 30624, Indonesia
}

\begin{abstract}
Internet users in Indonesia always increase every year. The highest increase occurred in smartphone internet users. The increase was due to a shift in the provision of software from desktop and web to mobile based. Based on these conditions it is necessary to know the process of providing mobile applications to suit users. Provision of mobile applications cannot be separated from the process of software development, especially the development of mobile software. For this reason, in this study a discussion on mobile software development methods consisting of wireless development, mobile application development lifecycle models (MADLC) and mobile development (Mobile-D) was discussed. the three methods of developing mobile wireless development software have the longest working phase, which is eight phases, while the mobile application development lifecycle model (MADLC) has seven phases and mobile development (Mobile-D) has five phases. The choice of mobile software development methods is an important factor in the development process.
\end{abstract}

Keywords: software development, mobile, MADLC, Mobile-D, Wireless Development

\begin{abstract}
Abstrak
Pengguna internet di Indonesia setiap tahunya selalu meningkat. Peningkatan yang paling tinggi terjadi pada pengguna internet smartphone. Peningkatan tersebut disebabkan adanya pergeseran penyediaan perangkat lunak dari desktop dan web ke berbasis mobile. Berdasarkan kondisi tersebut perlu untuk diketahui proses penyediaan aplikasi mobile agar sesuai dengan pengguna. Penyediaan aplikasi mobile tidak terlepas dari proses pegnembangan perangkat lunak terutama pengembangan perangkat lunak mobile. Untuk itu didalam kajian ini dilakukan pembahasan metode pengambangan perangkat lunak mobile yang terdiri dari wireless development, mobile application development lifecycle model (MADLC) dan mobile development (Mobile-D). Dari ketiga metode pengembangan perangkat lunak berbasis mobile wireless development memili fase pengerjaan paling Panjang yaitu delapan fase, sedangkan mobile application development lifecycle model (MADLC) memiliki tujuh fase dan mobile development (Mobile-D) memiliki lima fase. Pemilihan metode pengembangan perangkat lunak mobile menjadi faktor penting dalam proses pengembangan.
\end{abstract}

Kata kunci: pengembangan perangkat lunak, mobile, MADLC, Mobile-D, Wireless Development 


\section{PENDAHULUAN}

Perkembangan aplikasi mobile berbasis smartphone setiap saat mengalami peningkatan. Kondisi tersebut dapat dilihat dari jumlah pengguna yang mengakses internet melalui smartphone selalu meningkat dari tahun ke tahun (APJII, 2018). Pengguna internet yang mengakses melalui smartphone dapat dipastikan menggunakan aplikasi mobile. Jenis aplikasi mobile juga menjadi salah satu faktor penting dalam menigkatnya akses internet melalui smartphone. Untuk menghasilkan aplikasi mobile yang sesuai dengan kebutuhan pengguna perlu dilakukan pengembangan yang sesuai dengan kaidah pengembangan perangkat lunak. Sehingga pemilihan metode pengembangan menjadi sangat penting bagi seorang pengembang. Metode pengembangan perangkat lunak merupakan metode manajemen dalam melakukan proses pengembangan (Ependi, 2018). Tujuan digunakannnya metode pengembangan perangkat lunak agar tercapainya kebutuhan pengguna dan menghasilkan perangkat lunak yang terstandarirsasi (Ependi and Suyanto, 2016). Saat ini perkembangan perangkat lunak yang digunakan pengguna telah mulai bergeser dari sebelumnya berbasis desktop dan web dan sekarang beralih ke berbasis mobile. Sesuai kondisi tersebut maka perlu dilakukan pengkajian bagaimana proses pengembangan perangkat lunak khusus untuk mobile.

Saat ini terdapat bermacam-macam metode pengembangan perangkat lunak diantaranya adalah mobile application development process, wireless development, mobile application development lifecycle model (MADLC), Agile Methodology for Mobile Software Development, MASAM methodology, Mobile Application Development Methodology, dan Mobile Development (Mobile D) (Stapić et al., 2016). Setiap motode pengembangan memiliki karateristik yang berbeda-beda sehingga memerlukan perlakuan yang berbeda pula. Selain itu juga dalam pengembangan perangkat lunak metode yang digunakan haruslah sesuai dengan bentuk atau jenis perangkat lunak yang dikembangkan. Kondisi tersebut disebabkan tidak semua metode cocok untuk jenis perangkat lunak yang akan dikembangkan. Jenis perangkat lunak sendiri terdapat berbagai macam diantaranya adalah system software, application software engineering/scientific software, open world computing, ubiquitous computing, netsourcing, data mining, grid computing, dan cognitive machines (Pressman, 2012). Sehingga pemilihan metode perangakt lunak bagi seorang pengembang menjadi hal yang sangat penting agar menghasilkan perangkat lunak yang berkualitas sesuai standar.

Berdasarkan uraian yang telah dikemukakan sebelumnya dan melihat pentingnya pengetahuan bagi seorang pengembanga dalam memilih metode pengembangan maka penulis akan melakukan kajian pustaka berkaitan metode pengembangan perangkat lunak mobile. Pemilihan metode pengembangan perangkat lunak mobile sendiri disebabkan saat ini terjadinya pergeseran yang cukup massif dikalangan penyedia perangkat lunak dari desktop dan web ke mobile. Agar semakin terarahnya kajian yang dilakukan maka metode pengembangan perangkat lunak mobile yang kaji meliputi wireless development, mobile application development lifecycle model (MADLC) dan mobile development (Mobile-D). dari ketiga metode pengembangan tersebut akan digali bagaimana proses yang dilakukan untuk setiap metode serta kelebihan dan kekurangannya. 


\section{METODOLOGI PENELITAN}

Kajian yang dilakukan merupakan kajian kualitatif dengen penggalian teoritis. Kajian kualitatif bertujuan untuk menjawab perumusan masalah yang berkaitan dengan metode pengembangan perangkat lunak berbasis mobile. Sehingga penggunaan pendekatan kajian kualitatif agar lebih mudah memahami keadaan dari sudut pandang peneliti. Untuk itu dapat dikatakan bahwa kajian kualitatif merupakan bentuk kajian yang berfokus pada peneliti sebagai instrument kunci dalam menilai objek tertentu (Rahardjo, 2017). Selain itu juga kedalam data/informasi menjadi focus dari kajian kualitatif. Maka detail informasi yang didapat akan mempengaruhi hasil kajian. Dengan demikian semakin baik kualitas data/informasi yang didapat maka semakin baik pula hasil kajin (Ependi et al., 2019). Pada Gambar 1 dapat dilihat proses penelitian yang dilakukan.

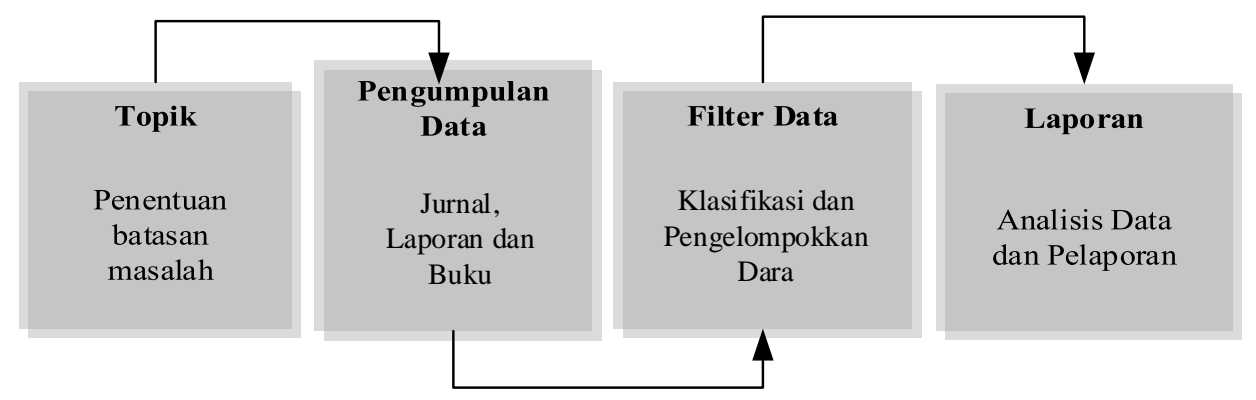

Gambar 1. Proses kajian metode pengembangan mobile

Proses kajian seperti yang diperlihatkan pada Gambar 1 dilakukan mulai dari penentuan topik, dimana dalam proses penentuan topik dilakukan pembatasan msalah kajian yaitu pemilihan metode pengembangan mobile yang akan dibahas yaitu wireless development, mobile application development lifecycle model (MADLC) dan mobile development (Mobile-D). setelah topik yang akan dibahan ditentukan selanjutnya dilakukan pengumpulan data baik berupa artikel pada jurnal mapun prosiding, laporan dan buku yang terkait. Ketika data berupa artikel jurnal, laporan ataupun buku yang telah dikumpulkan didapat maka selanjutnya dilakukan pengelompokkan data antara yang relevan maupun yang tidak relevan. Data yang relevan dimasukkan sebagai kajian dalam bentuk laporan berupa artikel.

\section{HASIL DAN PEMBAHASAN}

Dari rumusan maslah dan metode yang telah disampaikan maka datapat dijelaskan untuk masing-msaing metode pegnembangan baik wireless development, mobile application development lifecycle model (MADLC) maupun mobile development (Mobile-D) sebagai berikut. 


\subsection{Wireless Development}

Metode pengembangan wireless development memiliki delapan tahapan dalam pengembangan aplikasi mobile seperti yang diperlihatkan pada Gambar 2 berikut ini.

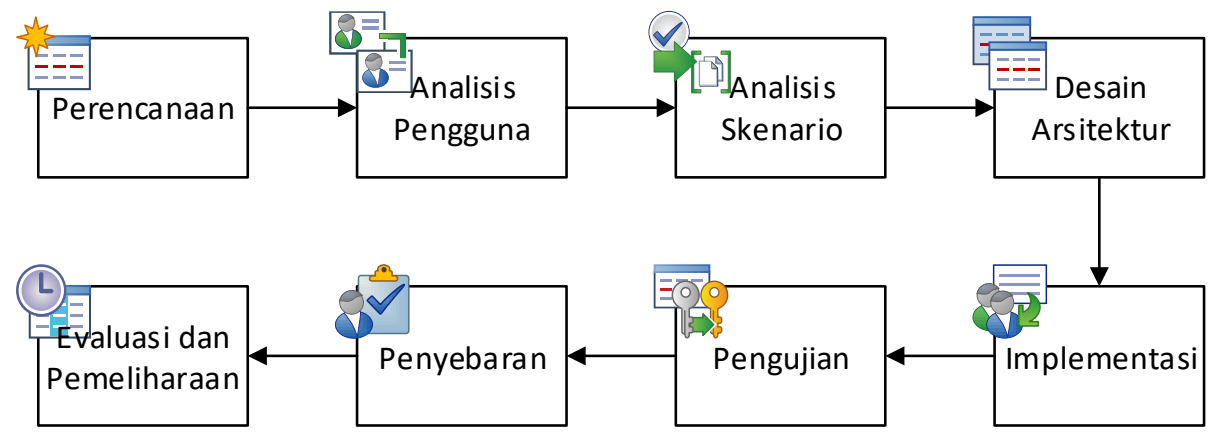

Gambar 2. Proses Pengembangan Perangkat Lunak (Ependi et al., 2017)

Proses pegnembangan perangkat lunak mobile yang terlihat pada Gambar 2 yang dimulai dari perencaan, analisis pengguna, analisis scenario, desain arsitektur, implementasi, pengujian, penyebaran, evaluasi \& penyebaran dapat dijelaskan sebagai berikut (Simarmata, 2010).

(1) Perencanaan, Tahap perencanaan aktivitas yang dilakukan adalah menetapkan ruang lingkup dari perangkat lunak. Ruang lingkup tersebut meliputi batasan pekerjaan dan jadwal pengerjaan perangkat lunak.

(2) Analisis Pengguna, Tahapan ini peneliti melakukan analisis pengguna perangkat lunak dan lingkungan tempat operasinya. Pada tahapan ini juga akan menghasilkan siapa saja aktor dari perangkat lunak dan aktivitas yang dapat dilakukan.

(3) Analisis Skenario, Tahapan ini dilakukan analisis kebutuhan perangkat lunak konvensional. Oleh karena itu, pada tahapan ini akan dihasilkan skenario skenario perangkat lunak yang dibuat berdasarkan hasil analisa pengguna mobile.

(4) Desain Arsitektur, Tahap ini berkaitan dengan keseluruhan arsitektur (atau struktur) dari perangkat lunak baik cara pengasesan maupun antarmuka. Dalam melakukan desain arsitektur tools yang digunakan adalah Microsoft visio baik untuk arsitektur pengkasesan maupun antarmuka.

(5) Impelementasi, Pada tahap ini pekerjaan yang dilakukan adalah menterjemahkan hasil desain ke dalam bentuk pengkodeaan. Tools yang digunakan untuk membangun perangkat lunak ini adalah Eclips dan basis data mysql.

(6) Pengujian, Tahapan ini dilakukan pengujian perangkat lunak. Pengujian dilakukan menggunakan pendekatan black box. Pengujian dilakukan untuk melihat fungsional perangkat lunak apakah sesuai yang kebutuhan atau tidak.

(7) Penyebaran, Tahapan ini dilakukan publikasi perangkat lunak yang telah dilakukan pengujian. Publikasi perangkat lunak yang dihasilkan akan disebarkan 
melalui jejaring play store dan melalui media koran agar dapat diinstalasi oleh pengguna.

(8) Evaluasi Pelanggan dan Pemeliharan, Tahapan ini peneliti melakukan evaluasi dan pemeliharaan setelah perangkat lunak telah dipublikasikan. Jika ada masukkan untuk perbaikan maka dilakukan perbaikan

\subsection{Mobile application development lifecycle model (MADLC)}

Metode pengembangan mobile application development lifecycle model (MADLC) terdiri dari tujuh tahapan seperti yang diperlihatkan pada Gambar 3.

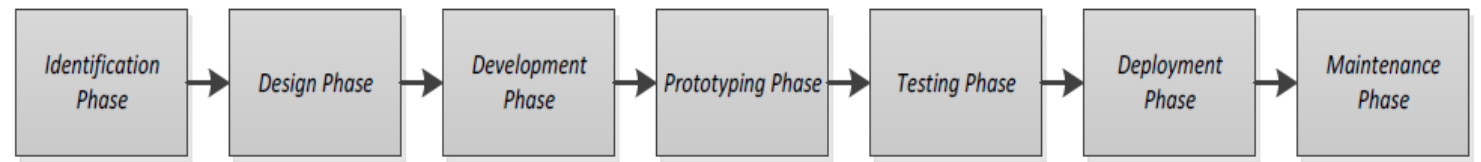

Gambar 3. Metode pengambangan MADLC (Vithani and Kumar, 2014)

Dari fase metode MADLC seperti yang diperlihatkan pada Gambar 3 dapat dijelaskan pekerjaan setiap fase sebagai berikut (Ependi, 2016):

(1) Identification phase: fase ini memiliki tujuan utama mendapatkan ide baru dengan cara melakukan brainstorming. Ide yang dihasilkan divisualkan dalam bentuk diagram fungsional kebutuhan perangkat lunak. Dalam penelitian ini ide yang dihasilkan akan digambarkan dalam bentuk uml diagram yaitu berupa use case diagram.

(2) Design phase: fase ini melakukan penterjemahan ide awal menjadi desain storyboard untuk interaksi antarmuka pengguna. Hasil desain akan digunkan untuk melakukan pengkodean. Dalam penelitian ini desain yang akan dibuat berupa desain antarmuka pengguna aplikasi berdasarkan kebutuhan fungsional perangkat lunak sesuai dengan yang digambarkan pada use case diagram.

(3) Development phase: fase ini dilakukan pengkodean berdasarkan hasil perancangan yang dilakaukan pada fase desain. Dalam penelitian ini pengkodean dilakukan mengacu pada hasil perancangan antarmuka pada fase sebelumnya menggunakan visual studio untuk android.

(4) Prototyping phase: fase ini dilakukan analisis untuk masing-masing hasil pengkodean berupa fungsional prototype. Dalam penelitian ini prototype diuji dan dikirim kepada stakeholder untuk mendapatkan umpan balik. Setelah umpan balik diterima maka dilakukan perbaikan sesuai denan umpan balik yang diberikan. Ketika prototype kedua telah siap, maka dilakukan integrase dengan prototype pertama lalu diuji dan kemudian dikirim ke stakeholder. Proses tersebut dilakukan terus menerus sampai dengan selesainya aplikasi.

(5) Testing Phase: fase ini adalah salah satu tahapan paling penting dari setiap pengembangan perangkat lunak. Pengujian dapat dilakukan pada emulator / simulator dan juga dilakukan pengujian pada perangkat nyata. Dalam penelitian 
ini pengujian perangkat lunak dilakukan pada perangkat nyata berupa melakukan installasi perangkat lunak pada perangkat mobile dengan sistem operasi android dengan beberapa versi android. Selain itu juga pengujian dilakukan untuk melihat tampilan terabaik perangkat lunak pada ukurang-ukuran layar perangkat mobile.

(6) Deployment phase: fase ini merupakan tahap akhir dari proses pengembangan. Setelah pengujian selesai dan umpan balik yang terakhir diperoleh dari stakeholder, aplikasi siap untuk disebarkan dengan cara dilakukan packaging ke dalam file installer berdasarkan sistem operasi yang diinginkan. Dalam penelitian ini dilakukan khusus untuk perangkat mobile dengan sistem operasi android.

(7) Maintenance phase: pemeliharaan adalah tahap akhir dari proses pengembangan. Pemeliharaan adalah proses yang berkesinambungan. Dalam penelitian ini pemeliharaan dilakukan berdasarkan masukkan yang diberikan oleh pengguna perangkat lunak, jika ada masukkan maka akan dilakukan perbaikan.

\subsection{Mobile development (Mobile-D)}

Metode pengembangan dengan menggunakan mobile development (Mobile-D) terdapat lima fase proses pengerjaan seperti yang diperlihatkan pada Gambar 4 berikut ini.

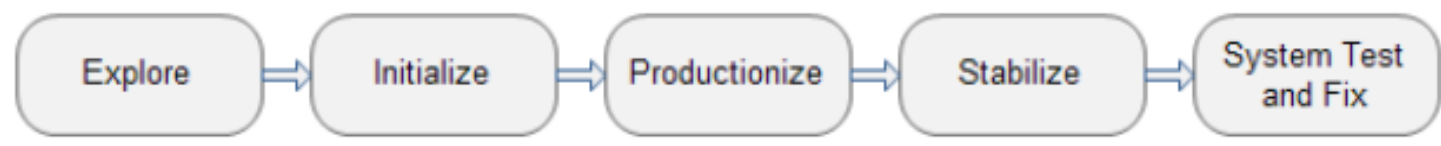

Gambar 4. Metode pengembangan Mobile-D(Abrahamsson et al., 2004)

Dari fase proses pengembangan seperti yang diperlihatkan pada Gambar 4 maka dapat dijelaskan aktivitas yang dilakukan didalamnya sebagai berikut (Flora and Chande, 2013):

(1) Explore, tahapan ini dilakukan perencanaan dan penyusunan rencana terhadap projek yang akan dikerjakan. Tahap ini juga dilakukan strukturisasi pondasi pengembangan perangkat lunak mobile. Strukturisasi tersebut meilupu arsitektur produk, proses pengembangan dan lingkungan pengembangan.

(2) Initialize, tahapan ini dilakukan penyiapan dan verifikasiterhadap isu-isu yang akan dihadapi pada proses pengembangan yang berdampak pada keberhasilan proyek. Tahap ini diakhiri dengan hasil perancangan perangkat lunak mobile.

(3) Productionize, tahapan ini adalah tahapan pengimplementasian dari perancangan berdasrakan semua kebutuhan fungsional pada perangkat lunak mobile yang dilakukan secara iterative dan bertingkat. 
(4) Stabilize, tahapan ini dilakukan penyatuan/integrasi sub komponen aplikasi yang telah dibangun menjadi satu kesatuan perangkat lunak mobile yang dilakukan secara iterative dan bertingkat.

(5) System test and fix, tahapan ini dilakukan pengujian dan dilakukan pernbaikan jiga terdapat kesalahan (Ependi, 2017).

\section{KESIMPULAN}

Berdasarkan uraian yang telah dikemukkan maka dapat disimpulkan sebagai berikut yaitu (1) pemilihan metode pengembangan perangkat lunak mobile menjadi sangat penting karena akan berpengaruh pada proses pengerjaannya. (2) Dari ketiga metode pengembangan perangkat lunak berbasis mobile wireless development memili fase pengerjaan paling Panjang yaitu delapan fase, sedangkan mobile application development lifecycle model (MADLC) memiliki tujuh fase dan mobile development (Mobile-D) memiliki lima fase. (3) Pemilihan metode pengembangan perangkat lunak mobile menjadi faktor penting dalam proses pengembangan.

\section{REFERENSI}

ABRAHAMSSON, P., HANHINEVA, A., HULKKO, H., IHME, T., JÄÄLINOJA, J., KORKALA, M., KOSKELA, J., KYLLÖNEN, P. \& SALO, O. Mobile-D: an agile approach for mobile application development. Companion to the 19th annual ACM SIGPLAN conference on Object-oriented programming systems, languages, and applications, 2004. ACM, 174-175.

APJII 2018. Indonesia Internet Service Provider Association: Penetrasi dan Perilaku Pengguna Internet Indonesia. In: 2017, S. (ed.). Jakarta, .

EPENDI, U. 2016. Solusi Mudah Belajar Matematika Tingkat Sekolah Dasar Menggunakan Perangkat Lunak Model MADLC. Jurnal Teknik Informatika dan Sistem Informasi, 2, 130-140.

EPENDI, U. 2017. Mobile Application Monitoring Pengisian Uang Anjungan Tunai

Mandiri PT Bank Mandiri Cabang Palembang. Jurnal Edukasi dan Penelitian Informatika, 3, 33-39.

EPENDI, U. 2018. Implementasi Model Scrum pada Sistem Informasi Seleksi Masuk

Mahasiswa Politeknik Pariwisata Palembang. Jurnal Informatika: Jurnal Pengembangan IT, 3, 49-55.

EPENDI, U., KURNIAWAN, T. B. \& PANJAITAN, F. 2019. SYSTEM USABILITY SCALE VS HEURISTIC EVALUATION: A REVIEW. Simetris: Jurnal Teknik Mesin, Elektro dan Ilmu Komputer, 10, 65-74.

EPENDI, U., PANJAITAN, F. \& HUTRIANTO, H. 2017. WIRELESS DEVELOPMENT SEBAGAI MODEL PENGEMBANGAN PERANGKAT LUNAK MOBILE MEDIA PENDUKUNG ASIAN GAMES XVIII. Prosiding SNaPP: Sains, Teknologi, 7, 87-97. 
EPENDI, U. \& SUYANTO, S. 2016. Implementasi Location Based Service Pada Aplikasi Mobile Pencarian Halte BRT Transmusi Palembang. Journal of Information Systems Engineering and Business Intelligence, 2, 33-39.

FLORA, H. K. \& CHANDE, S. V. 2013. A review and analysis on mobile application development processes using agile methodologies. International Journal of Research in Computer Science, 3, 8-18.

PRESSMAN, R. 2012. Software Engineering: A Practitioner's Approach, McGrawHill.

RAHARDJO, M. 2017. Studi kasus dalam penelitian kualitatif: konsep dan prosedurnya. Malang: Universitas Islam Negeri Maulana Malik Ibrahim Malang.

SIMARMATA, J. 2010. Rekayasa Perangkat Lunak, Yogyakarta, Andi Ofset.

STAPIĆ, Z., MIJAČ, M. \& STRAHONJA, V. Methodologies for development of mobile applications. 2016 39th International Convention on Information and Communication Technology, Electronics and Microelectronics (MIPRO), 2016. IEEE, 688-692.

VITHANI, T. \& KUMAR, A. Modeling the Mobile Application Development Lifecycle. Proceedings of the International MultiConference of Engineers and Computer Scientists, 2014. 12-14. 